\title{
Stem Cell Therapy in Wound Healing and Tissue Regeneration
}

\author{
Anna Meiliana ${ }^{1,2,}$, Nurrani Mustika Dewi ${ }^{1,2}$, Andi Wijaya ${ }^{1,2,3}$ \\ ${ }^{1}$ Postgraduate Program in Clinical Pharmacy, Padjadjaran University, Jl. Eijkman No.38, Bandung, Indonesia \\ ${ }^{2}$ Prodia Clinical Laboratory, Jl. Cisangkuy No.2, Bandung, Indonesia \\ ${ }^{3}$ Postgraduate Program in Clinical Biochemistry, Hasanuddin University, J1. Perintis Kemerdekaan Km.10, Makassar, Indonesia \\ *Corresponding author. E-mail: anna.meiliana@prodia.co.id
}

Received date: Feb 8, 2016; Revised date: Apr 27, 2016; Accepted date: May 22, 2016

\section{Abstract}

$\mathrm{B}$ ACKGROUND: Recent advances in our basic knowledge of the tissue damage and regeneration pathology have combined with a remarkable progress in stem cell biology so the prospect of clinical tissue repair strategies is a tangible reality. We tried to describe a better view about mesenchymal stem cell (MSC) mechanisms in wound healing and tissue regeneration, sending any ideas for next advanced therapies.

CONTENT: Sustaining injury, whether minor or major, is part of every organism life. Therefore, efficient response mechanisms to damage have developed. Wound healing is a perplexing multi-step processes which can be divided into three major phases: inflammation, proliferation, and scar formation/remodeling. Though the compartementalization of this process into discrete stages give the illusion of simplicity, but in reality it is much more complicated. So that efficient healing can occur, complex interactions between multiple cell types, soluble factors and extracellular matrix components are required to rebuild the tissue. Even under optimal conditions, the healing process drives to fibrosis or scar. The latest technology that makes a huge difference in the wound healing process is stem cell therapy, which offers a novel approach to many diseases.

SUMMARY: Wound healing therapies continue to rapidly evolve, with advances in basic science and engineering research heralding the development of new therapies, as well as ways to modify existing treatments. Stem cell-based therapy is one of the most promising therapeutic concepts for wound healing. Advances in stem cell biology have enabled researchers and clinicians alike with access to cells capable of actively modulating the healing response.

KEYWORDS: wound healing, tissue regeneration, stem cells therapy

Indones Biomed J. 2016; 8(2): 61-70

\section{Introduction}

For centuries, biologists have marveled at the ability of organisms such as salamanders to regrow near perfect copies of amputated body parts through a precisely orchestrated process called epimorphic regeneration. Epimorphic regeneration occurs via the formation of a blastema, a mass of undifferentiated and differentiated cells containing a heterogeneous pool of progenitor cells. The few mammalian tissues which are capable of regenerating, such as blood, skeletal muscle and epithelium, renew predominantly through stem cells, instead of forming a blastema. However, stem cell-based regeneration has not proven widely effective for most tissues plagued by degenerative processes such as the heart and nervous system.(1) We tried to describe a better understanding about the role of mesenchymal stem cell (MSC) in wound healing and tissue regeneration mechanisms in this review, perhaps to send any ideas for a more comprehensive and effective therapy in wound healing.

Regenerative medicine is defined as the process of creating living, functional tissues to repair or replace tissue or organ function lost due to age, disease, damage or congenital defects. Because of their extensive ability to self-renew and to generate differentiated progeny, 
stem cells are the focus of many applications in regenerative medicine. $(2,3,4)$ Regenerative medicine is an emerging field with the potential to reduce the need for organ transplantation. It refers to the mechanisms where adult organisms restore form and function to damaged tissues and organs, focusing on three main aspects, each of which has drawbacks. First, the elucidation of mechanistic aspects of embryonic development is crucial to understanding regeneration, however, the field is far from yielding therapeutically applicable outcomes from this knowledge. Second, studying adult tissue turnover and replacement in an evolutionary context, using efficiently regenerating vertebrate species such as fish or salamanders to analyze mechanisms of repair often seems distant from a mammalian perspective and relatively slow to yield mechanistic information. Third, the identification and use of adult and pluripotent stem cells in regenerative medicine has attracted huge scientific and public interest, but until now their clinical application to tissue repair has had minimal impact. Human clinical stem cell therapy studies are being performed and have often utilized autologous stem cells but have not typically focused on modification of the target tissue to optimize their effect.(5)

Wounds, both chronic and acute, continue to be a tremendous socioeconomic burden. As such, technologies drawn from many disciplines within science and engineering are constantly being incorporated into innovative wound healing therapies.(6) Healing a wound is, no matter how simple the organization of a cellular system, always the result of sequential steps, where each one taking the damaged area one step closer to restoring cellular architecture and function. $(7,8,9)$ If tissue integrity and homeostasis are about to be restored in the moments after an injury occurs, various intracellular and intercellular pathways must be activated and coordinated. Cellular components of the immune system, the blood coagulation cascade and the inflammatory pathways are activated in addition. Many types of cell, including immune cells (neutrophils, monocytes, lymphocytes and dendritic cells), endothelial cells, keratinocytes and fibroblasts, undergo marked changes in gene expression and phenotype, leading to cell proliferation, differentiation and migration. $(10,11)$ If this response is successful and the injury does not result in the downfall of the organism, these processes must be shut down in a precise sequence in the following days as recovery progresses.(12,13) For most injuries, repair results in once functional tissue becoming a patch of cell, mainly fibroblasts, and disorganized extracellular matrix (ECM), mainly collagen, which is usually referred to as a scar. Surprisingly, in some eukaryotic organisms, the response to injury can perfectly recapitulate the original tissue architecture, through the incompletely understood process of regeneration. Humans have this ability during the prenatal development, but it is lost during adult life.(14) How regeneration occurs and why humans lose this ability remain a mystery.(15)

Problems with wound healing mostly manifest in human can be either delayed wound healing (happens a lot in diabetic patients or radiation exposure), or excessive healing resulted in hypertrophic and keloid scars, due to large amounts of ECM deposit and alteration in local vascularization folowed with cell proliferation. This excessive reactions often known as "bad scar".(16) The goal of such research is an ancient one, described in the Greek myth of Prometheus, that is to change wound healing from a process of imperfect repair to complete regeneration.(6)

\section{The Cell Biology of Regeneration}

Regeneration of complex structures after injury requires dramatic changes in cellular behavior. Regenerating tissues initiate a program that includes diverse processes such as wound healing, cell death, dedifferentiation, and stem (or progenitor) cell proliferation. Moreover, newly regenerated tissues must integrate polarity and positional identity cues with preexisting body structures.(17) Gene knockdown approaches and transgenesis-based lineage and functional analyses have been instrumental in deciphering various aspects of regenerative processes in diverse animal models for studying regeneration. $(9,17)$

After amputation, local responses at the site of the wound play important roles in the initiation of regenerative processes. Wound healing, ion flux, and interactions between the wound epidermis and the underlying tissue appear urgently important for regenerative outgrowth. $(16,18)$ Recent work offers that programmed cell death may play a role in triggering regenerative responses in many different organisms.(19) Apoptotic cells have been observed during early phases of regeneration in several animals that can regenerate missing tissues, for examples planarians, xenopus, and newts.(20-24) Apoptotic cells have been shown to provide a number of signals that can regulate wound healing and regeneration. Mitogen-activated protein (MAP) kinases signaling through Jun kinase is important both for initiating apoptosis and production of wingless/ integrated (Wnt) and bone morphogenic protein (BMP) mitogens.(25-27) The further to which these factors are 
required for stimulating compensatory proliferation remains unclear.

Injury-induced apoptotic signals are also necessary to maintain tissue homeostasis. When cells of the adult Drosophila midgut are injured by toxins or induced to undergo apoptosis, intestinal enterocytes secrete the cytokine. Unpaired, which prompts proliferation of intestinal stem cells through activation of the Jak/Stat pathway.(28) Similarly, in the mouse intestine massive induction of apoptosis via intestine-specific knockout of the p53 inhibitor mouse double minute 2 homolog (Mdm2), it is eventually compensated in adults by increased proliferation and expansion of the stem cell pool.(29) Apoptotic cells also contribute to homeostasis in epithelia by lipid-based signaling, for example sphingosine-1-phosphate, which triggers actomyosin contraction in the surrounding cells, leading to the extrusion of the dying cells.(30) These observations suggest many potential roles for dead and dying cells to alter cell behavior at sites of injury.

New cells can be generated in a sort of ways, including proliferation of a resident stem cell population, division of terminally differentiated cells, or dedifferentiation/ transdifferentiation of mature cells to a stem cell-like precursor or another cell type. The extent to which each mode is used differs between species and even across tissues within the same species.(17) The source of regenerative cells in vertebrates varies between tissues and organisms, and in some cases stays as a matter of continued debate. Mature stem cells contained in many vertebrate tissues play important role in tissue regeneration, turnover and homeostasis in several contexts through the process of division, dedifferentiation, and transdifferentiation. In extreme damage or chronic liver disease, liver progenitor cells appear to be the major sources for new hepatocytes regeneration, while in partial hepatectomy or mild liver injury the liver mass restoration majority accomplished through proliferation of remaining hepatocytes.(31) Similarly, recent lineage-tracing experiments indicate that after damage to the zebrafish heart, the existing cardiomyocytes undergo dedifferentiation and proliferate to generate new cardiomyocytes for replacing lost heart mass. $(4,32,33)$

Investigations of model organisms have begun to characterize the cellular sources of regeneration, define their potency, and also identify molecules required for restorative events. Therefore, there is a great opportunity for cell biological studies to link gene function to cellular behavior in the moment. One of the long-term goals of regeneration research is to understand why humans have such limited regenerative potential and what can be done to improve it, if there is any. The knowledge acquired from studying cell biological questions in model organisms should supports turn such future efforts of regenerative medicine.

The Process and Molecular Mechanisms of Wound Healing

The capacity to respond to injury and to repair tissue is a fundamental property of all multicellular organisms. But there is astounding diversity in how this process occurs. Studying wound repair in various phyla could improve our understanding of wound repair in humans and might help to identify molecules or pathways that can be targeted to restore the lost regenerative capacity. In general, the wound repair process happens in almost all tissues after exposure to almost any destructive stimulus. Thus, the sequence of events that follows a myocardial infarction (heart attack), for example, is remarkably similar to that following a spinal-cord injury, a burn or a gunshot wound, despite the different types of insult and the different organs affected. Likewise, scar formation which occurred during wound repair leads to similar tissue dysfunction wherever it takes place. In the case of myocardial infarction, the formation of myocardial scar tissue is thought to result in congestive heart failure, a condition in which the heart cannot supply body's tissues with enough blood, and/or abnormal heart rhythms (arrhythmias).(16)

Wound healing is an essential biological process that consists of sequential steps aimed at restoring the architecture and function of damaged cells and tissues.(8) Traditionally, mammalian wound healing is described as occurring in three overlapping stages: inflammation, proliferation and remodeling (Figure 1).(16) The process of wound healing technically starts at the moment of injury with inflammation. The body's initial response, formation of a fibrin clot, provides hemostasis and recruits several types of cells to the wound.(34) The first circulating immune cells to arrive are neutrophils, with highest concentrations found 1 to 2 days post-injury. They function in preventing bacterial infection (given the disrupted epithelial barrier) as well as in activation of keratinocytes, fibroblasts and immune cells.(34,35) Early migration of keratinocytes along the temporary fibrin ECM is seen within hours of wounding.(10)

Circulating monocytes arrive and differentiate into macrophages 2-3 days after the injury. During the early inflammatory phase of wound healing, macrophages 

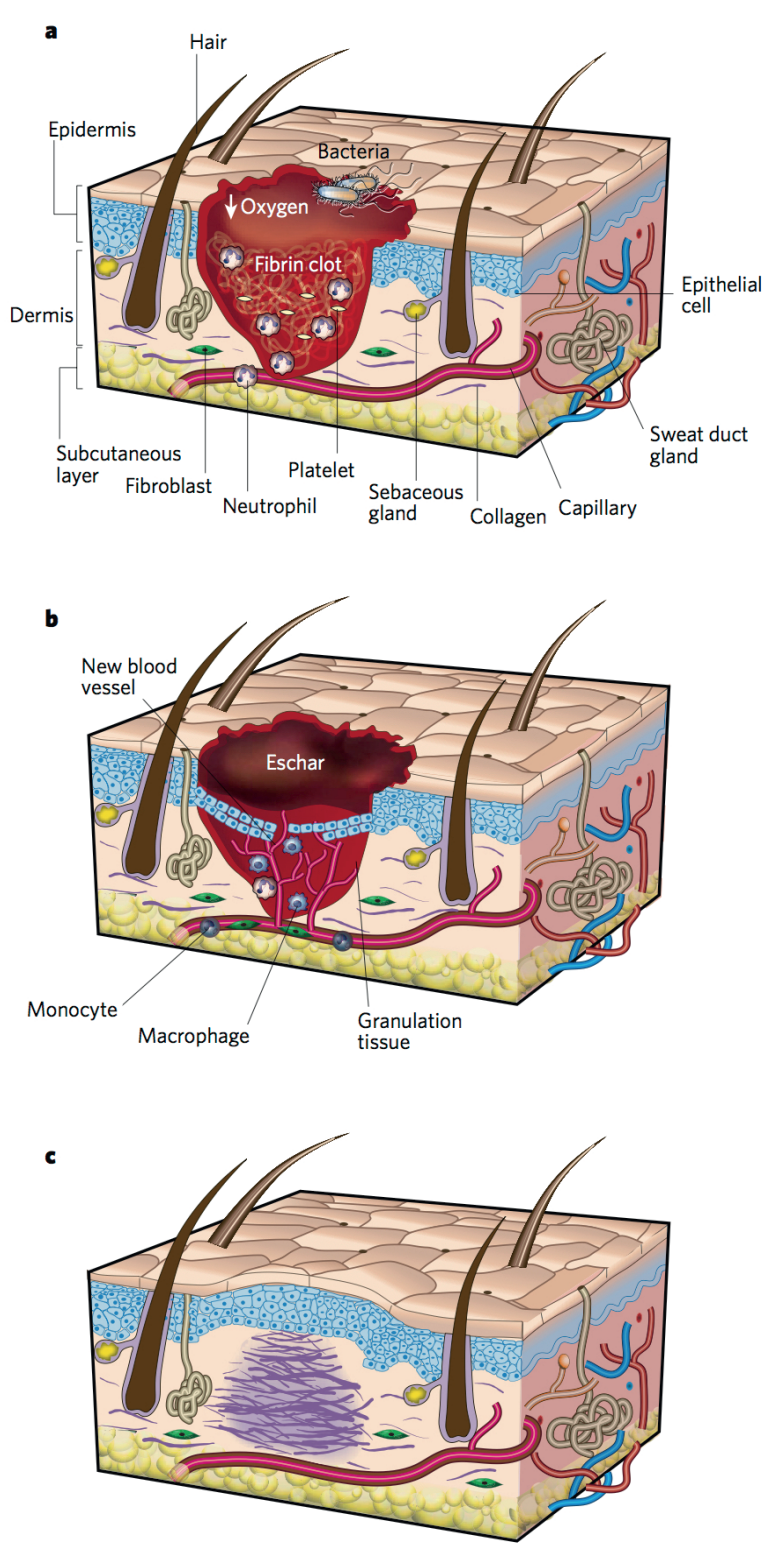

Figure 1. Cancer Classic stages of wound repair. There are three classic stages of wound repair: inflammation (a), new tissue formation (b) and remodeling (c).(20) (Adapted with permission from Nature Publishing Group).

function alongside neutrophils in preventing infection and help to debride the wound of necrotic tissue. $(16,36)$ As the inflammatory stage of wound healing ends and proliferation begins, macrophages adopt an anti-inflammatory, profibrotic phenotype. The growth factors they produce, such as transforming growth factor (TGF)- $\beta$, recruit fibroblasts from the surrounding uninjured tissue. $(34,36)$ These and other cells stimulate the migration of endothelial cells into the wound via production of vascular endothelial growth factor (VEGF), among other factors, resulting in the formation of new blood vessels and, thus, the hypervascular character of granulation tissue.(37)
Completion of re-epithelialization is also attained during the proliferative stage of wound healing. This process involves migration, proliferation and differentiation of keratinocytes drawn from both wound edges and stem cell populations found in the hair follicle bulge region.(38) Despite the participation of stem cells, epidermal appendages are not regenerated during wound healing.(34) Re-epithelialization is aided by the production of a replacement ECM by fibroblasts. Components of the ECM such as fibronectin, along with cytokines such as TGF- $\beta 1$ and certain inflammatory mediators produced during the immune response to injury, induce fibroblast activation.(39-41) Activated fibroblasts, or myofibroblasts, so named due to the contractile ability provided by their expression of alpha smooth muscle actin ( $\alpha$-SMA), respond physically and biochemically to the mechanical environment of the wound. Physically they contract, adequating to bring the edges of the wound together, decreasing its overall size. $(16,42)$ They are also responsible for the secretion of the abnormal ECM-characterizing scar tissue.(43) This ECM primarily varies from that of unwounded skin and mature scars in its collagen content, containing increased levels of immature type III collagen, which is relative to the mature type I collagen that predominates in normal skin and mature scar. $(6,43)$

Comprehensive understanding in normal and pathological wound healing process, either cellular or molecular will provide the possibility for more targeted, efficient therapy development. Knowing the stem cells multipotent and self-renewing properties, along with their low immunogenicity, stem cell application give a positive opportunity for another emerging paradigm for acute and chronic wound treatment. Stem cells from a variety of sources have proven to be successful in experimental wound healing applications, and are now being tested in many preclinical and clinical trials.(44)

\section{Tissue Regeneration in Wound Healing and Fibrosis}

Dysfunctional healing results in either a persistent open wound, or excessive, disorganized cellular proliferation driving to a hypertrophic or keloid scar. Both of these extremes of wound healing can lead to significant functional impairment, psychosocial morbidity and overall increased health-care costs.(6) Fibrosis is an immensely conserved and coordinated protective response to tissue injury. The interaction of multiple pathways, molecules and systems 
determines whether fibrosis is self-limiting and homeostatic, or whether it is uncontrolled and excessive. Immune cells have been identified as key players in this fibrotic cascade, which have the capacity to exert either injury-inducing or repair-promoting effects. A multi-organ approach was recently suggested to identify the core and regulatory pathways in fibrosis, aiming to integrate the wealth of information emerging from basic fibrosis research.(45)

Dysfunctional inflammation has also been implicated in hypertrophic scarring. Specifically, hypertrophic scars are related to a prolonged inflammatory phase of wound healing. This may be associated with the mechanism of injury, as they typically occur after burn injury or other trauma to the deep dermis.(46) In contrast, keloid formation is determined by both genetic and environmental factors: they are predominantly seen in darker skinned individuals and the propensity to form them can be inherited. $(47,48)$ Clinically, both hypertrophic scars and keloids present as pruritic, raised, reddened and firm masses, although a keloid will extend beyond the borders of the original wound.(49) They may be both cosmetically distressing and, due to scar contractures, functionally debilitating. $(50,51)$ While a hypertrophic scars will partially regress (undergo a remodeling phase), a keloid will not.(48)

Fibrosis becomes problematic and clinically relevant when dysregulated and excessive scarring occurs in response to persistent injury and drives to altered tissue function. Healing by fibrosis, instead of regeneration, places a huge burden on public health. The total economic cost of diseases which is resulted from fibrosis is difficult to calculate precisely, but it is of the order of tens of billions of dollars.(52) Importantly, dysfunctional healing often causes lifelong disability, which has a significant economic impact.(11) Thus, if fibrotic healing processes can be transformed into regenerative ones, in which the original tissues are restored, this would considerably improve human health.(16) Stem cell-based therapy is one of the most promising therapeutic concepts for wound healing. Advances in stem cell biology have enabled researchers and clinicians alike with access to cells capable of actively modulating the healing response.(6)

\section{The Role of Macrophages in Wound Healing and Tissue Regeneration}

Macrophages found in all tissues, play a role in tissue development, homeostasis, repair and immunity, known as the most plastic cells in the haematopoeietic system as they show great functional diversity. They are anatomically different from one to another, and have a different transcriptional profiles and functional capabilities, but they are all required for tissue homeostasis maintenance. However, subverted of nay of these reparative and homeostatic functions due to chronic insults, can result in a macrophages associated disease states.(53) Macrophages likely represent the pre-eminent cells in the body endowed with the ability to migrate within tissues, even in hypoxic conditions, and with the capacity to modify the ECM and amplify paracrine signals.

Wound healing is a complex biological process that occurs frequently during adulthood and requires the interplay among different cell types, including keratinocytes, fibroblasts and immune cells.(54) Early studies suggested that macrophages and neutrophils play a crucial role during skin wound healing. Macrophages are generally believed to orchestrate the repair process by acting both as phagocytes, to clear cellular debris, and as a major source of growth factors (e.g., proangiogenic factors, epithelialcell growth factors, etc.).(55) Depletion of macrophages during the subsequent phase of the repair response (tissue formation) caused severe hemorrhage in the wound tissue and prevented tissue maturation and wound closure. Macrophage depletion during the late stage of repair (tissue maturation) did not significantly impact the outcome of the repair response. These interesting observations suggest that macrophages exert distinct functions during the diverse phases of skin repair. In particular, macrophages appear to play an important role in promoting angiogenesis in the granulation tissue during the early phase of skin repair, and in vascular maturation and stabilization in the subsequent phases.(56) Distinct types of wound healing macrophages have been described to date. Their phenotypic and functional characterization is, however, not yet exhaustive.(54)

Recruitment of macrophages to the wound healing site may rely on different signals, such as chemokine C-C motif ligand 2 (CCL2)/monocyte chemotactic protein 1 (MCP1), macrophage inflammatory protein-1alpha (MIP1 $\alpha$ ), but also stromal cell-derived factor 1 (SDF1)/ C-X-C motif chemokine 12 (CXCL12) and granulocytecolony stimulating factor (G-CSF).(57) Okuno and coworkers showed that colony stimulating factor (CSF)-1 is early up-regulated at the wound healing site and play an important role in recruiting macrophages.(58) Thus, wound healing macrophages may exert their proangiogenic programs by physically interacting with sprouting blood vessels, facilitating their growth by degrading the ECM, and/or promoting vascular 
remodeling via non-canonical (e.g., VEGF-independent) angiogenic pathways.(59)

Sindrilaru and co-workers recently reported that human chronic venous ulcers contain increased proportions of macrophages markers (e.g., nitric oxide synthase (NOS) 2 and tumor necrosis factor (TNF)- $\alpha$ than healing wounds.(60) Successful mammalian regeneration requires precise coordination of multiple processes, which include scavenging cellular debris, proliferation and activation of progenitor cells, immune modulation, angiogenesis and innervation of the newly forming tissue.(1)

Following conditioning by the inflammatory milieu including local growth factors and cytokines, macrophages polarize into classically activated (M1) or alternatively activated (M2) subtypes based on their markers, function, and cytokine profiles.(55) Typically, M1 cells produce high levels of pro-inflammatory cytokines and NOS which aid in host defense but can also damage healthy tissue while M2 macrophages mediate wound healing, tissue repair and the resolution of inflammation. Nevertheless, M1 cells can also have a positive role in tissue regeneration. In the heart and skeletal muscle, early infiltration by M1 macrophages facilitates clearance of necrotic tissue $(61,62)$, and disrupting macrophage polarization impairs healing and regeneration, respectively (63).

Perhaps the strongest link between immune-mediated debris clearance and regenerative capacity has been documented in the central nervous system (CNS) and demyelinating diseases (Figure 2). The sensitivity of the CNS to debris clearance may be attributed to the plentiful inhibitory properties of myelin, the membrane sheath that insulates axons, when deposited in damaged tissue. While remyelination is robust in the CNS of young, healthy mice, the ability to restore the myelin sheath declines with age or in disease. Clearance of myelin debris depends on macrophages and recent data suggest that the decline in efficient CNS regeneration is linked to the immune system.(64)

Study by Heredia, et al., showed that skeletal muscle regeneration was mediated by interleukin (IL)-4-secreting eosinophils which activating fibro/adipocyte progenitors (FAP) for necessary debris clearance to enhance the effective regeneration. In the absence of IL-4, FAPs do not clear debris, but instead differentiate into adipocytes, which contribute to muscle degeneration (Figure 2).(1)

In kidney regeneration, macrophage-derived Wnt7b is needed for renal tubular epithelial regeneration.(65) Cross-talk between the immune system and progenitor cell populations mediated by critical modulators of cell to cell signaling such as Notch and Wnt therefore seems to be a generally known regenerative signaling pathway in different tissues. The immune system also affects progenitor and stem cells by creating the appropriate microenvironment for their development and function (Figure 3).(1)

Both arms of the immune response are required for repair in many systems, for examples in heart, skeletal muscle, and the CNS. If initial, pro-inflammatory signals are not controlled, for example, excessive tissue damage can occur and block repair. Conversely, premature initiation of the anti-inflammatory program can also disrupt efficient tissue healing; for example, skeletal muscle regeneration is impaired when macrophages are prematurely skewed by treatment with IL-10 or genetic loss of MAP kinase phosphatase-1 (MKP-1).(63) Also, in both skeletal muscle regeneration and remyelination, M1 macrophages recruit and stimulate progenitor proliferation while M2 macrophages mediate differentiation, dispelling the common view that M1 macrophage responses are overall bad while M2 are good.(1)

The re-establishment of adequate blood flow to injured and newly forming tissue is a key aspect of regeneration. Immune cells help developmental angiogenesis by secreting soluble factors, remodeling matrix and physically pruning and supporting the vasculature during the maturation process. In the developing mouse retina, vessel remodeling is under the control of macrophages via expression of the Wnt ligands Wnt5a and Wnt11 (66), that enhance the

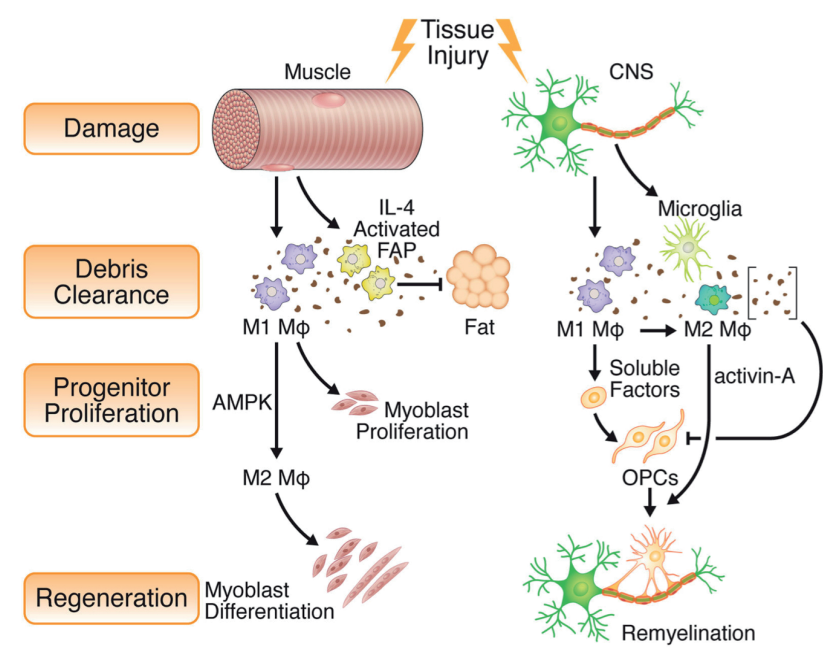

Figure 2. Debris clearance as a coordinator of regeneration. Debris clearance orchestrated by the immune system is a key activator of subsequent steps in regeneration, including progenitor cell activation, differentiation, and immune polarization.(1) MØ: macrophage; AMPK: AMP-activated protein kinase, OPC: oligodendrocyte precursor cell. (Adapted with permission from Elsevier). 


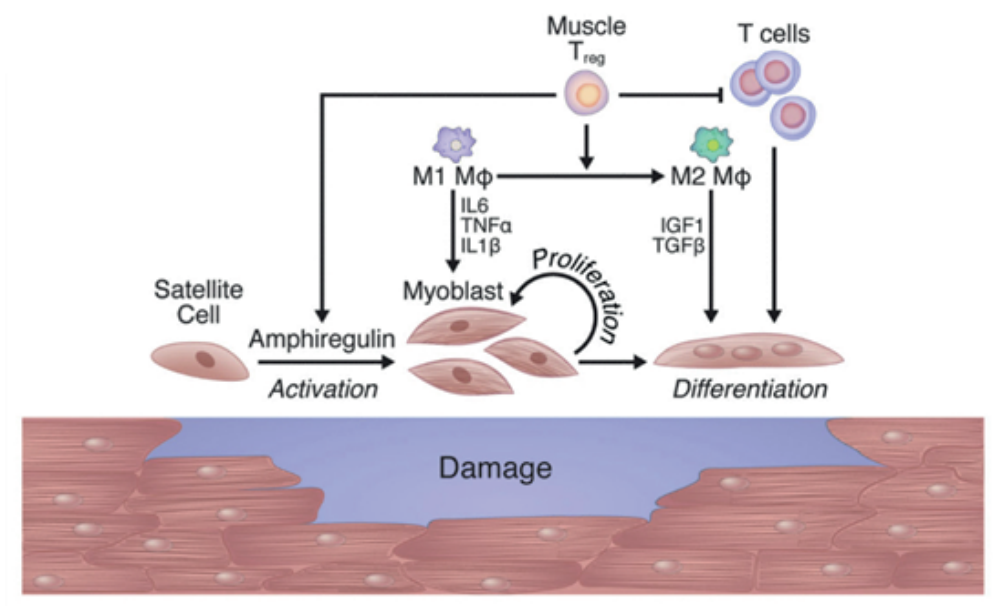

Figure 3. Immune cell polarization and heterogeneity are key components of tissue repair or regeneration. The regenerative capacity of skeletal muscle is driven by satellite cell activation, proliferation and differentiation. (1) MØ: macrophage; IGF: insulin-like growth factor. (Adapted with permission from Elsevier). expression of the VEGF inhibitory receptor Fms-Related Tyrosine Kinase 1 (FLT1). Interestingly, genetic disruption of the myeloid non-canonical Wnt pathway can enhance wound angiogenesis and repair, suggesting the same signaling pathway found in the retinal vasculature could have therapeutic applications for modulating myeloid cell signaling to treat wounds.(67) The significance of immune regulation of angiogenesis, progenitor cell activity, debris removal, and appropriate polarization of subsequent immune responses and soluble factor secretion suggests that a closer look at pro-regenerative therapeutics targeted at immunity is warranted.

\section{MSC in Wound Repair and Regeneration}

MSCs are multipotent cells which have the capacity for self-renewal and differentiation and have a wide tissue distribution. These characteristics make them candidate cells for wound healing and regeneration in different kind of disorders. Endogenous and exogenously delivered MSCs can traffic and migrate to injured tissue, participating in tissue healing process. Even the concentrated conditioned medium from MSCs can modulate wound repair without MSCs themselves being present in the tissue. This suggest that MSC therapeutic effects acquired through their ability to differentiate and transdifferentiate into tissue-specific cells, to fuse with the native cells, and to stimulate resident cells survival and functional recovery by secreting a parade of paracrine factors which regulate the local microenvironment (niche) and immune response.(68)

MSCs may be obtained from different areas in the body, with the most generally known sources being bone marrow (BM-MSC) and adipose tissue (ASC). While differences in the phenotype of BM-MSCs and ASCs have been observed, both have proven to be efficacious in wound healing therapies.(69) MSC that appears to be a native constituent of the wound bed (70), have emerged as an alternative to the standard pharmaceutical treatment modalities. These cells are critical trophic mediators to promote tissue regeneration and can be readily derived from a variety of autologous or allogeneic adult tissues, also from commercial providers.(71) The versatility of these cells has made them an attractive candidate for clinical translation in many different therapeutic applications. In particular, MSCs may offer the means of recapitulating several mechanisms which are sufficient for inhibition of scar formation in skin wounds.(72)

If the inflammatory phase is prolonged, the proinflammatory mediators will direct the wound healing cells, such as myofibroblasts and fibrocytes, in generating the nonfunctional, void-filling tissue that will result in the formation of a scar.(73) Scars are a consequence of cutaneous wound healing that can be both unsightly and detrimental to the function of the tissue. After the MSCs enter the inflammatory environment, their immunomodulatory phenotype becomes activated by interferon (IFN)- $\gamma$, TNF- $\alpha$ and IL- $1 \beta$.(74) The ability of MSCs to regulate T-cell recruitment, proliferation and activity is well documented.(74,75) There is also evidence that MSCs are able to suppress the proliferation of B cells (76) and natural killer cells (77), through ameliorating the acute immune response to injury. By attenuating the function of these cell types, the MSCs would likely reduce the pro-fibrotic responses which can occur coincident with the prolonged inflammation during wound healing. $(78,79)$

Angiogenesis is an important process during the proliferation phase of wound healing to provide the fibroblasts with sufficient nutrient supply for the production of a provisional granulation matrix.(80) Unsuccessful in generating an adequate microvascular can induce wound 
closure deficiencies, develop into a chronic non-healing wound. Another important thing is a stable transitional vessels as the tissue remodels and forming a permanent vascular network. MSCs produce basic fibroblast growth factors (FGF) and VEGF-A, in addition to macrophages and fibroblasts, which provide powerful mitogenic cues to promote proliferation, migration and differentiation of microvascular endothelial cells. $(81,82)$ MSCs also express paracrine factors to promote vascular stability and vasoprotection $(83,84)$, including adrenomedullin (85). It has been hypothesized that these functions are unique to MSCs because of their possible perivascular origin, and they are able to exploit these functions to recreate their perivascular niche as the process of vasculature remodeling is concluded.(86)

More interesting and relevant is recent evidence showing that MSCs may transdifferentiate to epidermal cells, keratinocytes and microvascular endothelial cells under defined conditions in vitro.(87-89) Finally, MSCs may also transdifferentiate into keratinocytes under conditions that allow them to interact with native epidermal cells.(90) These studies suggest that MSCs could participate directly in the structural regeneration of dermal and epidermal tissues, so representing an additional mechanism by which the MSCs may promote cutaneous wound healing. Based on a variety of small and large animal studies, a growing body of evidence finds that MSCs provide significant benefit during dermal wound healing, as they can accelerate the rate of wound closure and re-epithelialization, improve the quality and strength of the regenerated tissue, recover wound healing pathologies that might otherwise result in a chronic, non-healing wound, and minimize the visual appearance of scar tissue.(72)

\section{Conclusion}

Wound healing is a dynamic process involving complicated interactions between multiple cell types, molecules and the ECM. What limited the development of the effective treatments for wound healing is the incomplete understanding of the pathophysiology of both normal and abnormal wound healing responses. Addition of certain growth factors and cytokines to wounds has resulted in improved wound healing, both in experimental models and clinically. An increasing understanding of stem cell biology has guided to the development of cell-based therapies able to affect multiple aspects of wound healing. Stem cell therapies hold huge promise as we continue to search for ways to regenerate damaged tissues. As our knowledge continues to improve, emerging technologies will allow for the development of safe, specialized wound therapies recreating the physical and chemical properties of the stem cell niche, potentially allowing for tissue regeneration as opposed to repair.

\section{References}

1. Aurora AB, Olson EN. Immune modulation of stem cells and regeneration. CellStem Cell. 2014; 15: 14-25.

2. Watt FM, Driskell RR. The therapeutic potential of stem cells. Philos Trans R Soc Lond B Biol Sci. 2010; 365: 155-63.

3. Lane SW, Williams DA, Watt FM. Modulating the stem cell niche for tissue regeneration. Nat Biotechnol. 2014; 32: 795-803.

4. Meiliana A, Dewi NM, Wijaya A. In search for anti-aging strategy. can we rejuvenate our aging stem cells? Indones Biomed J. 2015; 7 : $57-72$

5. Forbes SJ, Rosenthal N. Preparing the ground for tissue regeneration: from mechanism to therapy. Nat Med. 2014; 20: 857-69.

6. Zielins ER, Atashroo DA, Maan ZN, Duscher D, Walmsley GG, Hu M, et al. Wound healing: an update. Regen Med. 2014; 9: 817-30.

7. Sonnemann KJ, Bement WM. Wound repair: toward understanding and integration of single-cell and multicellular wound responses. Annu Rev Cell Dev Biol. 2011; 27: 237-63.

8. Cordeiro JV, Jacinto A. The role of transcription-independent damage signals in the initiation of epithelial wound healing. Nat Rev Mol Cell Biol. 2013; 14: 249-62.

9. Meiliana A, Wijaya A. Endothelial progenitor cells in diabetic vasculopathy. Indones Biomed J. 2009; 1: 4-23.

10. Singer AJ, Clark RA. Cutaneous wound healing. N Engl J Med. 1999; 341: 738-46.

11. Aarabi S, Longaker MT, Gurtner GC. Hypertrophic scar formation following burns and trauma: new approaches to treatment. PLoS Med. 2007; 4: e234.

12. Konigova R, Rychterova V. Marjolin's ulcer. Acta Chir Plast. 2000; 2: $91-4$

13. Trent JT, Kirsner RS. Wounds and malignancy. Adv Skin Wound Care. 2003; 16: 31-4.

14. Colwell AS, Longaker MT, Lorenz HP. Fetal wound healing. Front Biosci. 2003; 8: s1240-8.

15. Gurtner GC, Callaghan MJ, Longaker MT. Progress and potential for regenerative medicine. Annu Rev Med. 2007; 58: 299-312.

16. Gurtner GC, Werner S, Barrandon Y, Longaker MT. Wound repair and regeneration. Nature. 2008; 435: 314-21.

17. King RS, Newmrk PA. The cell biology of regeneration. J Cell Biol. 2012; 196: 553-62.

18. Levin M. Bioelectric mechanisms in regeneration: Unique aspects and future perspectives. Semin Cell Dev Biol. 2009; 20: 543-56.

19. Bergmann A, Steller H. Apoptosis, stem cells, and tissue regeneration. Sci Signal. 2010; 3: re8.

20. Hwang JS, Kobayashi C, Agata K, Ikeo K, Gojobori T. Detection of apoptosis during planarian regeneration by the expression of apoptosis-related genes and TUNEL assay. Gene. 2004; 333: 15-25.

21. Vlaskalin T, Wong CJ, Tsilfidis C. Growth and apoptosis during larval forelimb development and adult forelimb regeneration in the newt (Notophthalmus viridescens). Dev Genes Evol. 2004; 214: 423-31. 
22. Tseng AS, Adams DS, Qiu D, Koustubhan P, Levin M. Apoptosis is required during early stages of tail regeneration in Xenopus laevis. Dev Biol. 2007; 301: 62-9.

23. Chera S, Ghila L, Dobretz K, Wenger Y, Bauer C, Buzgariu W, et al. Apoptotic cells provide an unexpected source of Wnt3 signaling to drive hydra head regeneration. Dev Cell. 2009; 17: 279-89.

24. Pellettieri J, Fitzgerald P, Watanabe S, Mancuso J, Green DR, Sánchez Alvarado A. Cell death and tissue remodeling in planarian regeneration. Dev Biol. 2010; 338: 76-85.

25. Pérez-Garijo A, Shlevkov E, Morata G. The role of Dpp and Wg in compensatory proliferation and in the formation of hyperplastic overgrowths caused by apoptotic cells in the Drosophila wing disc. Development. 2009; 136: 1169-77.

26. Bergantiños C, Corominas M, Serras F. Cell death-induced regeneration in wing imaginal discs requires JNK signalling. Development. 2010; 137: 1169-79.

27. Morata G, Shlevkov E, Pérez-Garijo A. Mitogenic signaling from apoptotic cells in Drosophila. Dev Growth Differ. 2011; 53: 168-76.

28. Jiang H, Patel PH, Kohlmaier A, Grenley MO, McEwen DG, BA Edgar. Cytokine/Jak/Stat signaling mediates regeneration and homeostasis in the Drosophila midgut. Cell. 2009; 137: 1343-55.

29. Valentin-Vega YA, Okano H, Lozano G. The intestinal epithelium compensates for $\mathrm{p} 53$-mediated cell death and guarantees organismal survival. Cell Death Differ. 2008; 15: 1772-81.

30. Gu Y, Forostyan T, Sabbadini R, Rosenblatt J. Epithelial cell extrusion requires the sphingosine-1-phosphate receptor 2 pathway. J Cell Biol. 2011; 193: 667-76.

31. Riehle KJ, Dan YY, Campbell JS, Fausto N. New concepts in liver regeneration. J Gastroenterol Hepatol. 2011; 26 (Suppl 1): 203-12.

32. Jopling C, Sleep E, Raya M, Martí M, Raya A, Izpisúa Belmonte JC. Zebrafish heart regeneration occurs by cardiomyocyte dedifferentiation and proliferation. Nature. 2010; 464: 606-9.

33. Kikuchi K, Holdway JE, Werdich AA, Anderson RM, Fang Y, Egnaczyk GF, et al. Primary contribution to zebrafish heart regeneration by gata4(+) cardiomyocytes. Nature. 2010; 464: 6015 .

34. Baum CL, Arpey CJ. Normal cutaneous wound healing: clinical correlation with cellular and molecular events. Dermatol Surg. 2005; 31: 674-86.

35. Wilgus TA, Roy S, McDaniel JC. Neutrophils and wound repair: positive actions and negative reactions. Adv Wound Care. 2013; 2: $379-88$.

36. Sindrilaru A, Scharffetter-Kochanek K. Disclosure of the culprits: macrophages-versatile regulators of wound healing. Adv Wound Care. 2013; 2: 357-68.

37. Bao P, Kodra A, Tomic-Canic M, Golinko MS, Ehrlich HP, Brem H. The role of vascular endothelial growth factor in wound healing. J Surg Res. 2009; 153: 347-58.

38. Raja, Sivamani K, Garcia MS, Isseroff RR. Wound re-epithelialization: modulating keratinocyte migration in wound healing. Front Biosci. 2007; 12: 2849-68.

39. Midgley AC, Rogers M, Hallett MB, Clayton A, Bowen T, Phillips $\mathrm{AO}$, et al. Transforming growth factor-beta1 (TGF-beta1)stimulated fibroblast to myofibroblast differentiation is mediated by hyaluronan (HA)-facilitated epidermal growth factor receptor (EGFR) and CD44 co-localization in lipid rafts. J Biol Chem. 2013; 288: 14824-38.

40. Wynn TA, Ramalingam TR. Mechanisms of fibrosis: therapeutic translation for fibrotic disease. Nat Med. 2012; 18: 1028-40.

41. Gabbiani G. The myofibroblast in wound healing and fibrocontractive diseases. J Pathol. 2003; 200: 500-3.
42. Demidova-Rice TN, Hamblin MR, Herman IM. Acute and impaired wound healing: pathophysiology and current methods for drug delivery, part 1: normal and chronic wounds: biology, causes, and approaches to care. Adv Skin Wound Care. 2012; 25: 304-14.

43. Duffield JS, Lupher M, Thannickal VJ, Wynn TA. Host responses in tissue repair and fibrosis. Annu Rev Pathol. 2013; 8: 241-76.

44. Rennert RC, Rodrigues M, Wong VW, Duscher D, Hu M, Maan Z, et al. Biological therapies for the treatment of cutaneous wounds: Phase III and launched therapies. Expert Opin Biol Ther. 2013; 13 : 1523-41.

45. Pellicoro A, Ramachandran P, Iredale JP, Fallowfield JA. Liver fibrosis and repair: immune regulation of wound healing in a solid organ. Nat Rev Immunol. 2014; 14: 181-94.

46. Zhu Z, Ding J, Shankowsky HA, Tredget EE. The molecular mechanism of hypertrophic scar. J Cell Commun Signal. 2013; 7 : 239-52.

47. Halim AS, Emami A, Salahshourifar I, Kannan TP. Keloid scarring: understanding the genetic basis, advances, and prospects. Arch Plast Surg. 2012; 39: 184-9.

48. Al-Attar A, Mess S, Thomassen JM, Kauffman CL, Davison SP Keloid pathogenesis and treatment. Plast Reconstr Surg. 2006; 117: 286-300.

49. Ehrlich HP, Desmouliere A, Diegelmann RF, Cohen IK, Compton CC, Garner WL, et al. Morphological and immunochemical differences between keloid and hypertrophic scar. Am J Pathol. 1994; 145: $105-$ 13.

50. Schneider JC, Holavanahalli R, Helm P, Goldstein R, Kowalske K. Contractures in burn injury: defining the problem. J Burn Care Res. 2006; 27: 508-14.

51. Lawrence JW, Mason ST, Schomer K, Klein MB. Epidemiology and impact of scarring after burn injury: a systematic review of the literature. J Burn Care Res. 2012; 33: 136-46.

52. Klein L, O'Connor CM, Gattis WA, Zampino M, de Luca L, Vitarelli A, et al. Pharmacologic therapy for patients with chronic heart failure and reduced systolic function: review of trials and practical considerations. Am J Cardiol. 2003; 91: 18F-40F.

53. Wynn TA, Chawla A, Pollard W. Macrophage biology in development, homeostasis and disease. Nature. 2013; 496: 445-55.

54. Rodero MP, Khosrotehrani K. Skin wound healing modulation by macrophages. Int J Clin Exp Pathol. 2010; 3: 643-53.

55. Nucera S, Biziato D, De Palma M. The interplay between macrophages and angiogenesis in development, tissue injury and regeneration. Int J Dev Biol. 2011; 55: 495-503.

56. Lucas T, Waisman A, Ranjan R, Roes J, Krieg T, Müller W, et al. Differential roles of macrophages in diverse phases of skin repair. J Immunol. 2010; 184: 3964-77.

57. Gordon S, Martinez FO. Alternative activation of macrophages: mechanism and functions. Immunity. 2010; 32: 593-604.

58. Wu Y, Zhao RC, Tredget EE. Concise review: bone marrow-derived stem/progenitor cells in cutaneous repair and regeneration. Stem Cells. 2010; 28: 905-15.

59. Okuno Y, Nakamura-Ishizu A, Kishi K, Suda T, Kubota Y. Bone marrow-derived cells serve as proangiogenic macrophages but not endothelial cells in wound healing. Blood. 2011; 117: 5264-72.

60. Sindrilaru A, Peters T, Wieschalka S, Baican C, Baican A, Peter H, et al. An unrestrained proinflammatory M1 macrophage population induced by iron impairs wound healing in humans and mice. J Clin Invest. 2011; 121: 985-97.

61. Arnold L, Henry A, Poron F, Baba-Amer Y, van Rooijen N, Plonquet $\mathrm{A}$, et al. Inflammatory monocytes recruited after skeletal muscle injury switch into antiinflammatory macrophages to support myogenesis. J Exp Med. 2007; 204: 1057-69. 
62. Nahrendorf M, Swirski FK, Aikawa E, Stangenberg L, Wurdinger $\mathrm{T}$, Figueiredo JL, et al. The healing myocardium sequentially mobilizes two monocyte subsets with divergent and complementary functions. J Exp Med. 2007; 204: 3037-47.

63. Perdiguero E, Sousa-Victor P, Ruiz-Bonilla V, Jardi M, Caelles C, Serrano AL, et al. p38/MKP-1-regulated AKT coordinates macrophage transitions and resolution of inflammation during tissue repair. J Cell Biol. 2011; 195: 307-22.

64. Kotter MR, Li WW, Zhao C, Franklin RJ. Myelin impairs CNS remyelination by inhibiting oligodendrocyte precursor cell differentiation. J Neurosci. 2006; 26: 328-32.

65. Lin SL, Li B, Rao S, Yeo EJ, Hudson TE, Nowlin BT, et al. Macrophage Wnt7b is critical for kidney repair and regeneration. Proc Natl Acad Sci USA. 2010; 107: 4194-9.

66. Stefater JA 3rd, Ren S, Lang RA, Duffield JS. Metchnikoff's policemen: macrophages in development, homeostasis and regeneration. Trends Mol Med. 2011; 17: 743-52.

67. Stefater JA 3rd, Rao S, Bezold K, Aplin AC, Nicosia RF, Pollard JW, et al. Macrophage Wnt-Calcineurin-Flt1 signaling regulates mouse wound angiogenesis and repair. Blood. 2013; 121: 2574-8.

68. Li H, Fu X. Mechanisms of action of mesenchymal stem cells in cutaneous wound repair and regeneration. Cell Tissue Res. 2012; 348: 371-7.

69. Strioga M, Viswanathan S, Darinskas A, Slaby O, Michalek J. Same or not the same? Comparison of adipose tissue-derived versus bone marrow-derived mesenchymal stem and stromal cells. Stem Cells Dev. 2012; 21: 2724-52.

70. Badiavas EV, Abedi M, Butmarc J, Falanga V, Quesenberry P. Participation of bone marrow derived cells in cutaneous wound healing. J Cell Physiol. 2003; 196: 245-50.

71. Salem HK, Thiemermann C. Mesenchymal stromal cells: current understanding and clinical status. Stem Cells. 2010; 28: 585-96.

72. Jackson WM, Nesti LJ, Tuan RS. Mesenchymal stem cell therapy for attenuation of scar formation during wound healing. Stem Cell Res Ther. 2012; 3: 20.

73. Rhett JM, Ghatnekar GS, Palatinus JA, O'Quinn M, Yost MJ, Gourdie RG. Novel therapies for scar reduction and regenerative healing of skin wounds. Trends Biotechnol. 2008; 26: 173-80.

74. Ren G, Zhang L, Zhao X, Xu G, Zhang Y, Roberts AI, et al. Mesenchymal stem cell-mediated immunosuppression occurs via concerted action of chemokines and nitric oxide. Cell Stem Cell. 2008; 2: 141-50.

75. Chamberlain G, Fox J, Ashton B, Middleton J. Concise review: Mesenchymal stem cells: their phenotype, differentiation capacity, immunological features, and potential for homing. Stem Cells. 2007; 25: 2739-49.
76. Corcione A, Benvenuto F, Ferretti E, Giunti D, Cappiello V, Cazzanti F, et al. Human mesenchymal stem cells modulate B-cell functions. Blood. 2006; 107: 367-72.

77. Sotiropoulou PA, Perez SA, Gritzapis AD, Baxevanis CN, Papamichail M. Interactions between human mesenchymal stem cells and natural killer cells. Stem Cells. 2006; 24: 74-85.

78. Ashcroft GS, Yang X, Glick AB, Weinstein M, Letterio JL, Mizel DE, et al. Mice lacking Smad3 show accelerated wound healing and an impaired local inflammatory response. Nat Cell Biol. 1999; 1: 2606.

79. Redd MJ, Cooper L, Wood W, Stramer B, Martin P. Wound healing and inflammation: embryos reveal the way to perfect repair. Philos Trans R Soc Lond B Biol Sci. 2004; 359: 777-84.

80. Brown LF, Yeo KT, Berse B, Yeo TK, Senger DR, Dvorak HF, et al. Expression of vascular permeability factor (vascular endothelial growth factor) by epidermal keratinocytes during wound healing. J Exp Med. 1992; 176: 1375-9.

81. Gruber R, Kandler B, Holzmann P, Vogele-Kadletz M, Losert U, Fischer MB, et al. Bone marrow stromal cells can provide a local environment that favors migration and formation of tubular structures of endothelial cells. Tissue Eng. 2005; 11: 896-903.

82. Kaigler D, Krebsbach PH, Polverini PJ, Mooney DJ. Role of vascular endothelial growth factor in bone marrow stromal cell modulation of endothelial cells. Tissue Eng. 2003; 9: 95-103.

83. Lozito TP, Taboas JM, Kuo CK, Tuan RS. Mesenchymal stem cell modification of endothelial matrix regulates their vascular differentiation. J Cell Biochem. 2009; 107: 706-13.

84. Kato J, Tsuruda T, Kita T, Kitamura K, Eto T. Adrenomedullin: a protective factor for blood vessels. Arterioscler Thromb Vasc Biol. 2005; 25: 2480-7.

85. Renault MA, Roncalli J, Tongers J, Misener S, Thorne T, Jujo K, et $a l$. The Hedgehog transcription factor Gli3 modulates angiogenesis. Circ Res. 2009; 105: 818-26.

86. Bianco P, Robey PG, Simmons PJ. Mesenchymal stem cells: revisiting history, concepts, and assays. Cell Stem Cell. 2008; 2: 313-9.

87. Sasaki M, Abe R, Fujita Y, Ando S, Inokuma D, Shimizu H. Mesenchymal stem cells are recruited into wounded skin and contribute to wound repair by transdifferentiation into multiple skin cell type. J Immunol. 2008; 180: 2581-7.

88. Fu X, Fang L, Li X, Cheng B, Sheng Z. Enhanced wound-healing quality with bone marrow mesenchymal stem cells autografting after skin injury. Wound Repair Regen. 2006; 14: 325-35.

89 Lozito TP, Kuo CK, Taboas JM, Tuan RS. Human mesenchymal stem cells express vascular cell phenotypes upon interaction with endothelial cell matrix. J Cell Biochem. 2009; 107: 714-22.

90. Wu Y, Chen L, Scott PG, Tredget EE. Mesenchymal stem cells enhance wound healing through differentiation and angiogenesis. Stem Cells. 2007; 25: 2648-59. 